\title{
Physico-chemical interaction patterns of oxidized polyvinyl alcohol fraction with 4- and 5-aminosalicylic acids
}

\author{
(C) Galia G. Kutlugildina, Zalia F. Ramazanova, and Yury S. Zimin** \\ Department of Physical Chemistry and Chemical Ecology. Bashkir State University. \\ Zaki Validi St., 32. Ufa, 450074. Republic of Bashkortostan. Russia. \\ Phone: +7 (347) 229-96-94.E-mail:ZiminYuS@mail.ru
}

\begin{abstract}
*Supervising author; ${ }^{+}$Corresponding author Keywords: polyvinyl alcohol, oxidized fraction of polyvinyl alcohol, 4-aminosalicylic acid, 5-aminosalicylic acid, complexation, stability constants, thermodynamic parameters.
\end{abstract}

\begin{abstract}
The interaction of the oxidized fraction of polyvinyl alcohol (OF of PVA) with 4- and 5-aminosalicylic acids (4- and 5-ASA) in aqueous solutions was examined by ultraviolet spectroscopy. OF of PVA is obtained by oxidation of polyvinyl alcohol in an aqueous medium affected by hydrogen peroxide $(363 \mathrm{~K}$, [PVA] $=$ $3.5 \%$ wt., $\left[\mathrm{H}_{2} \mathrm{O}_{2}\right]=1 \mathrm{~mol} / 1, \mathrm{t}_{\text {oxid. }}=45 \mathrm{~min}$ ), further separated from the solution by acetone addition. The average molecular weight of the oxidized fraction of PVA, calculated from the experimentally found value of the characteristic viscosity using the Mark-Kun-Houwink equation, amounted to $4.5 \mathrm{kDa}$. It was found that the addition of the original (non-oxidized) polyvinyl alcohol to aqueous solutions of 4- and 5-ASA does not change their UV spectra. At the same time, the introduction of an oxidized fraction of polyvinyl alcohol into aqueous solutions of aminosalicylic acids leads to spectral changes, indicating intermolecular interactions and complexation. By the method of molar ratios, it was shown that in dilute aqueous solutions OF of PVA forms complex 1:1 compounds with 4-ASA and 5-ASA, i.e., one molecule of 4- or 5-aminosalicylic acid accounts for one carboxyl group of the oxidized PVA fraction. Using this method, in the 291-316 K temperature range, the stability constants $(\mathrm{K})$ of the resulting complex compounds were calculated. The results analised demonstrated that the oxidized fraction of polyvinyl alcohol forms strong enough complexes with 4- and 5aminosalicylic acids: the $\mathrm{K}$ values in the temperature range under study vary within $(1-7) \cdot 10^{4} 1 / \mathrm{mol}$. It was found out that with increasing temperature, the values of stability constants of complex compounds decrease. The study of the temperature dependence of $\mathrm{K}$ made it possible to determine the standard values of the changes in the Gibbs energy $\left(\Delta \mathrm{G}^{\circ}\right)$, enthalpy $\left(\Delta \mathrm{H}^{\circ}\right)$, and entropy $\left(\Delta \mathrm{S}^{\circ}\right)$ of complexing. Negative values of thermodynamic parameters indicate a spontaneous process of formation of complexes, their exothermicity and the resulting constraints of the movements of molecules.
\end{abstract}

\section{References}

[1] Encyclopedia of polymers. Vol.2. Moscow: Soviet Encyclopedia. 1974. P.910-990. (russian)

[2] N.S. Borisova, I.P. Koroleva, Yu.S. Zimin, A.R. Gimadieva, A.G. Mustafin. Spectrophotometric study of uracils interaction with apple pectin and its oxidation products. News of higher educational institutions. Chemistry and chemical technology. 2013. Vol.56. No.3. P.46-50. (russian)

[3] N.S. Borisova, G.R. Timerbaeva, Yu.S. Zimin, and A.G. Mustafin. Interaction of pectins with 4- and 5aminosalicylic acids. Butlerov Communications. 2013. Vol.34. No.4. P.59-64. ROI: jbc-02/13-34-4-59

[4] N.S. Borisova, G.G. Kutlugildina, Yu.S. Zimin, A.R. Gimadieva, A.G. Mustafin. Oxidizing destruction of arabinogalactan and its complex formation with uracils. News of higher educational institutions. Chemistry and chemical technology. 2014. Vol.57. No.9. P.62-66. (russian)

[5] Yu.S. Zimin, N.S. Borisova, G.R. Timerbaeva, A.R. Gimadieva, and A.G. Mustafin. Natural pectins: oxidative destruction and interaction with uracils. Butlerov Communications. 2015. Vol.42. No.4. P.1624. DOI: 10.37952/ROI-jbc-01/15-42-4-16

[6] Yu.S. Zimin, N.S. Borisova, G.R. Timerbaeva, A.R. Gimadieva, A.G. Mustafin. Preparation, toxicity, and anti-inflammatory activity of complexes of uracil derivatives with polyfunctional acids. Pharmaceutical Chemistry Journal. 2017. Vol.50. No.10. P.649-653. DOI: 10.1007/s11094-017-1507-5

[7] Yu.S. Zimin, N.S. Borisova, A.R. Gimadieva, and A.G. Mustafin. Structure, stability, toxicity and antiinflammatory activity of a complex of 5-hydroxy-6-methyluracil with 5-aminosalicylic acid. Butlerov Communications. 2017. Vol.49. No.3. P.12-21. DOI: 10.37952/ROI-jbc-01/17-49-3-12 
[8] Yu.S. Zimin, A.F. Ageeva, I.M. Borisov, Yu.B. Monakov. Oxidation of polyvinyl alcohol in water phase. I. Radical nature of process. News of higher educational institutions. Chemistry and chemical technology. 2006. Vol.49. No.1. P.52-57. (russian)

[9] Yu.S. Zimin, A.F. Ageeva, I.M. Borisov, Yu.B. Monakov. Oxidation of polyvinyl alcohol in water phase. II. Kinetic scheme of the process. News of higher educational institutions. Chemistry and chemical technology. 2006. Vol.49. No.2. P.58-62. (russian)

[10] Yu.S. Zimin. Kinetics and mechanism of ozonized oxidation of alcohols, esters, ketones and olefins in aqueous medium: Thesis for the degree of doctor of chemical sciences. Ufa: IOC USC RAS. 2006. 302p. (russian)

[11] A.F. Valieva. Kinetics and mechanism of the oxidation of the polyvinyl alcohol in aqueous medium: Thesis for the degree of candidate of chemical sciences. Ufa: IOC USC RAS. 2007. 154p. (russian)

[12] Yu.S. Zimin, I.M. Borisov, N.S. Borisova, A.G. Mustafin. Oxidation and destruction of polyvinyl alcohol in the aqueous phase. International Journal of Chemical Kinetics. 2013. Vol.45. No.12. P.821-831.

[13] Yu.S. Zimin, G.G. Kutlugil'dina, A.G. Mustafin. Preparing oxidized fractions of polyvinyl alcohol of a given molecular mass. Russian Journal of Physical Chemistry A. 2016. Vol.90. No.10. P.1993-1996. DOI: $10.1134 /$ S0036024416100344 (russian)

[14] Yu.S. Zimin, G.G. Kutlugil'dina, A.G. Mustafin. Oxidation and destruction of polyvinyl alcohol under the combined action of ozone-oxygen mixture and hydrogen peroxide. Russian Journal of Physical Chemistry A. 2018. Vol.92. No.3. P.419-423. DOI: 10.1134/S003602441803038X (russian)

[15] V.G. Belikov. Pharmaceutical Chemistry. Moscow: Vysshaya Shkola. 1985. 768p. (russian)

[16] M.D. Mashkovskiy. Drugs. Vol.1. Moscow: Novaya Volna Ltd. 2002. 540p. (russian)

[17] S.R. Rafikov, V.P. Budtov, Yu.B. Monakov. Introduction to the physical chemistry of polymer solutions. Moscow: Nauka. 1978. 328p. (russian)

[18] M.I. Bulatov, I.P. Kalinkin. Practical guidance by photometric methods of the analysis. Leningrad: Chemistry. 1986. 432p. (russian)

[19] M. Beck, I. Nadpal. Complexing studies via latest techniques. Moscow: Mir. 1989. 413p. (russian)

[20] O.M. Poltorak. Thermodynamics in physical chemistry. Moscow: Vysshaya Shkola. 1991. 320p. (russian) 